\title{
Seasonal Weather Variations in Khumbu Himal*
}

\author{
Tetsuzo Yasunari**
}

\begin{abstract}
Seasonal weather variations in Khumbu Himal are described on the basis of two full years of data (April 1973 to March 1975) at Lhajung station $(4420 \mathrm{~m})$. The data used are mainly the daily record of cloud, precipitation and moisture content, and the $500 \mathrm{mb}$ weather charts. It is suggested that each stage of seasonal weather variation in the high-altitude Himalayas in Nepal is mainly affected by: i) The Tibetan High in the monsoon season and the subtropical jet stream in the other seasons. ii) The moisture supply to this region from the Indian Ocean. There are also strong year to year variations depending on the strength of the subtropical jet stream and the Tibetan High.
\end{abstract}

\section{Introduction}

The important role of the Tibetan Plateau and the Himalayas on the atmospheric circulation in the northern hemisphere has been studied by many meteorologists. Their discussions are summarized as follows:

i) The topographical effect on the Subrtopical Jet Stream (STJ) as is seen in the sudden change of the jet axis in the pre- and post-monsoon seasons and in the steady location of the axis along the southern edge of the Himalayas in the winter season (Yin, 1949; Ramage, 1952; Staff Members, Academia Scinica, 1957-58).

ii) The thermal effect as a heat source during the monsoon season, producing a strong thermal anticyclone called the Tibetan High (Yeh, 1950; Murakami, 1958; Koteswaram, 1958; Flohn, 1968; Murakami, 1970) and also to cause the northward shift of the STJ.

The seasonal weather variation in the highland Himalaya is expected to depend directly upon the seasonal trend of the STJ and Tibetan High. To discuss cloud and precipitation phenomena, the seasonal variation of water vapor supply to this region should also be taken into account.

Reports on the seasonal weather variation of the high-altitude Himalayas over $4000 \mathrm{~m}$ based

* Glaciological Expedition to Nepal, Contribution No. 17

** Disaster Prevention Research Institute, Kyoto University, Uji-shi, Kyoto, 611 upon field observational data have been presented by only a few authors (Oi, 1954; Mueller, 1958;

Reiter and Heuberger, 1960; Osada, 1971), and their reports are not for the whole year but only for some part of the year (3 papers for premonsoon, 1 for postmonsoon and 1 for premonsoon through postmonsoon), because the data were provided mainly by mountaineering expeditions.

In this paper, considering the characteristic features mentioned above, the seasonal weather variation for two years at Lhajung station (4420 $\mathrm{m})$ in Khumbu Himal revealed form the daily data for cloudiness and precipitation are summarized and briefly discussed, along with some other weather elements at the same station and also upper air data. The period of analysis is almost two years (from April 1, 1973 to March, 15, 1975).

\section{Typical cloud patterns in the Khumbu region and diurnal variation of cloudiness observed at Lhajung station}

Cloud types and cloud amounts above and around Lhajung station were regularly observed 5 times a day from $0540(0600)$ to 1740 (1800) (Nepal Standard Time), especially at 2040 (2100) on the 10th, 20th and 30th. Some patterns of clouds and the diurnal variation of cloudiness are summarized below.

I. Convective dlouds $(\mathrm{Cu}, \mathrm{Sc})$ along the Imja Khola

These clouds are produced by the diurnal circulation along the Himalayan slope. They 
come up through the Imja valley from the southern and lower Himalayan foothills as the sun rises, and finally reach glacier zones of this valley at the latest by evening. On unstable weather days, they come up to the station earlier in the day, say at $0800-1000$, sometimes developing to cumulonimbus. On fine days, on the contrary, they come up later in day, to cover the station at about 1600-1700. In the monsoon they caused rain and drizzle through the night.

II. Convective clouds $(\mathrm{Cu}, \mathrm{Cb})$ around peaks and ridges of 5000-6000 m mountains.

These clouds are produced with convection promoted by strong radiative heating of the ground around peaks and ridges. They also develop after the sun rises, and soon cover peaks and ridges in this region. Precipitation around Lhajung is mainly attributed to this type of convective clouds. Around snowy peaks and ridges of higher altitude over $6000 \mathrm{~m}$ (for example, Ama Dablam, Nuptse, etc.), the development of the clouds of this type seems to be weak because of the relatively small absorption of solar radiation by the highly reflecitive snow cover and the relatively small content of water vapor at higher altitude.

On unstable weather days, convective clouds of type I and II both develop; occasionally it is difficult to distinguish them.

III. Stratus clouds (St) at night and in the early morning.

These clouds are observed mainly before sunrise and after sunset. Most of them are maintained by weakened convection or produced by radiative cooling of moist air in the evening and night.

IV. Upper clouds (Ci, Cc, Cs, Ac, As).

These clouds are frequently observed in the winter season, related to the upper westerly wave movement. Cirrus clouds $(\mathrm{Ci}, \mathrm{Cc}, \mathrm{Cs})$ are believed to be at a height of $9000 \mathrm{~m}$ or more. Altocumulus and altostratus (Ac, As) lie at about 8000-9000 $\mathrm{m}$, and only several peaks of the highest peaks (Sagarmatha, Lhotse, Makalu and Cho Oyu) can reach them. Sometimes in the winter season, as the upper wave trough approach, they (Ac, As) drop to about $6000 \mathrm{~m}$ and finally change to Nimbostratus (Ns), mixed with lower cumulus clouds. In the monsoon season, clouds of the cirrus group (especially, cirrus fibratus) are often found above the cumulus clouds. Schematic cloud patterns are shown in Fig. 1.

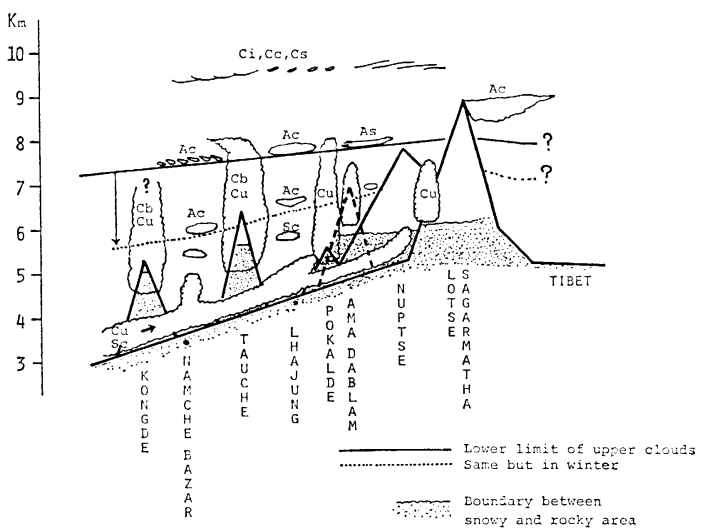

Fig. 1. Schematic cloud patterns in the Khumbu Region.

\section{Some characteristics of the seasonal weather variation}

The annual course of the diurnal variation of cloudiness (cloud amount is over 90\%) for about two years is shown in Fig. 2. In this figure, a time section of the daily $500 \mathrm{mb}$ contour pattern for $20^{\circ} \mathrm{N}$ through $50^{\circ} \mathrm{N}$ along $85^{\circ} \mathrm{E}$ (which crosses the middle of Nepal) is illustrated to see the relationship between the weather at the station and the upper air movement. In Fig. 3, daily values of water vapor pressure for the same period are plotted. The following discussion is based mainly on these two figures and the figure of daily precipitation in the Appendix.

\section{3-1 Beginning of premonsoon season.}

From the end of March, water vapor content began to increase as is shown in Fig. 3, and accordingly cumulus clouds ascending along the valley (type I clouds mentioned in the prvious section) increased day by day. The strength of the STJ over the Himalayas or northern India became weaker than in winter, and the STJ started to oscillate between north of Tibet and south of the Himalayas in accordance with the eastward progression of the westerly waves. This is a distinct characteristic for the beginning of the premonsoon season. Precipitation occurred from developed convective clouds, sometimes with thunder and lightning, when this region was situated at and ahead of a deep westerly trough embedded in the STJ. This weather regime is also reported at Everest Base Camp (Osada, 1971) and Yalung Kang Base Camp (Higuchi et. al., 1975). This may be explained as a vertically 

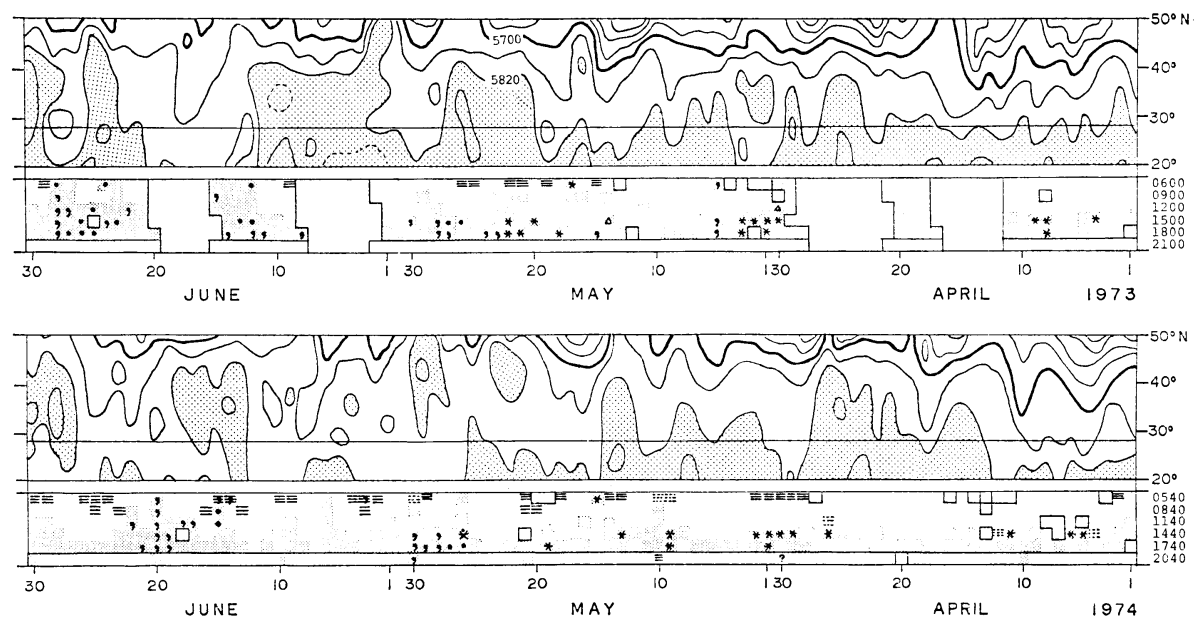

(A)
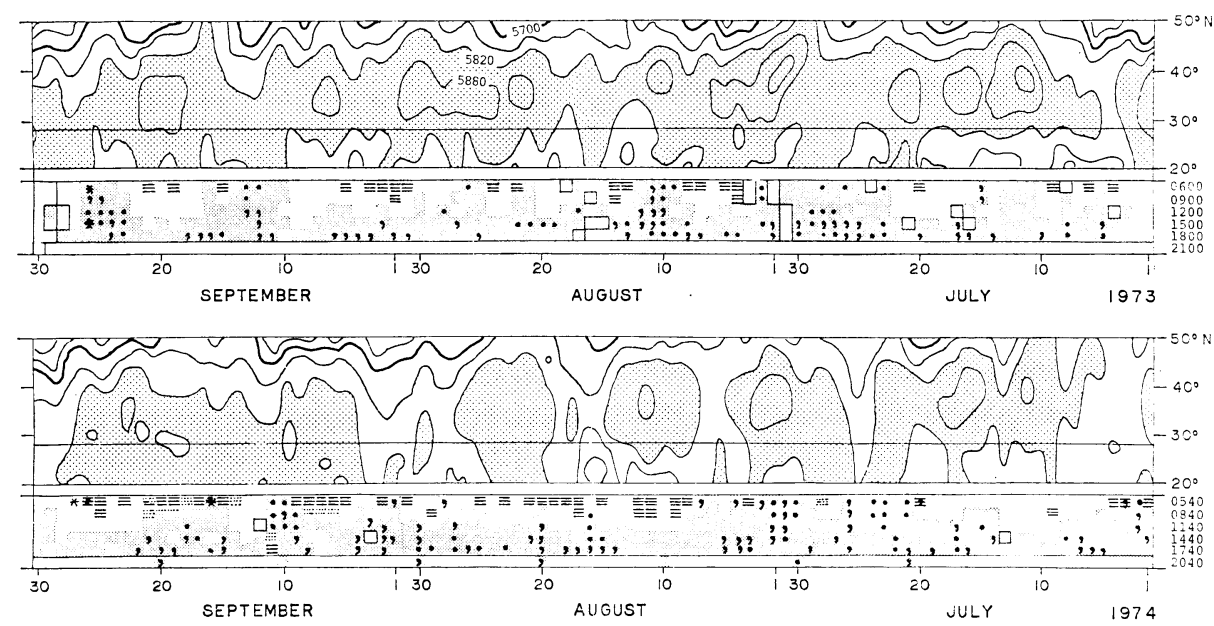

(B)
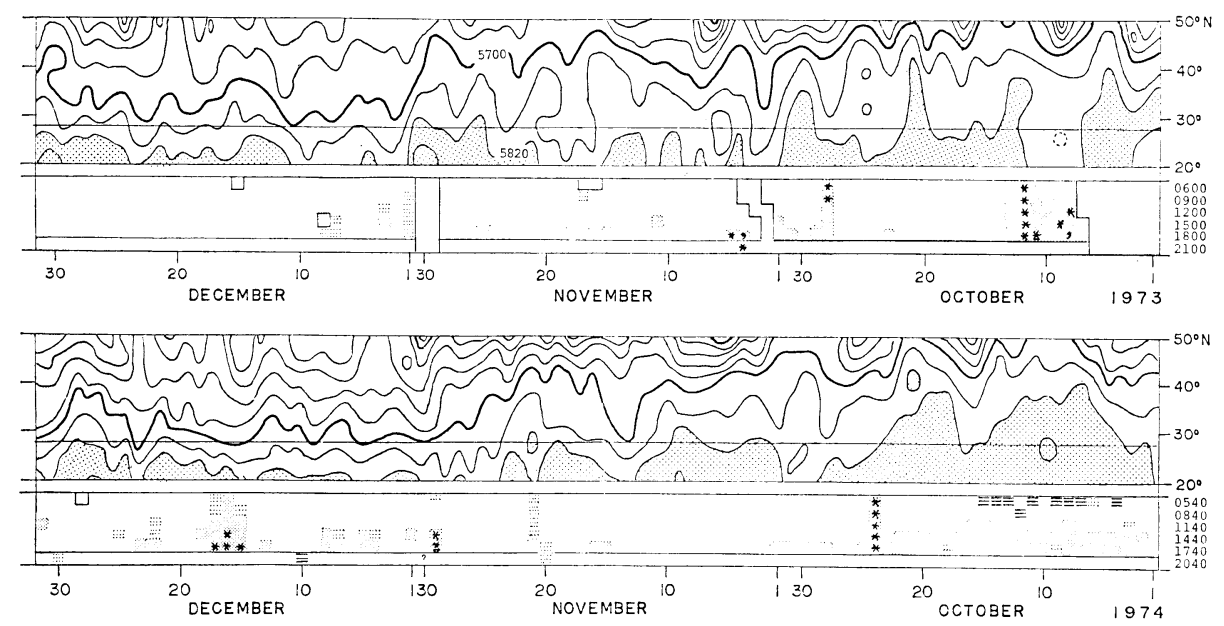

(C) 

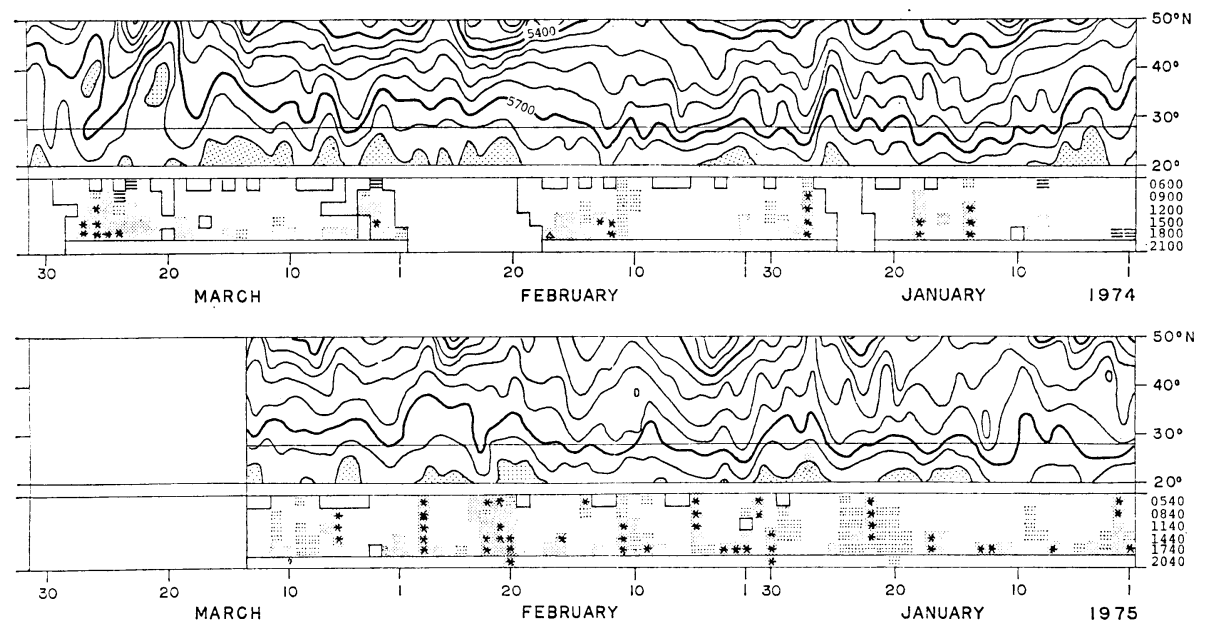

(D)

Fig. 2. Meridional time section of geopotential height at $500 \mathrm{mn}$ level along $85^{\circ} \mathrm{E}$ and daily frequency of cloudiness (cloud amount is over 90\%) of each observation time at Lhajung.

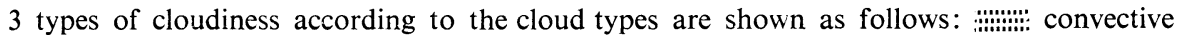
clouds $(\mathrm{Cb}, \mathrm{Cu}, \mathrm{Sc})$ and nimbostratus $(\mathrm{Ns})$, 三 stratus $(\mathrm{St}), \ldots$ Ac, As).

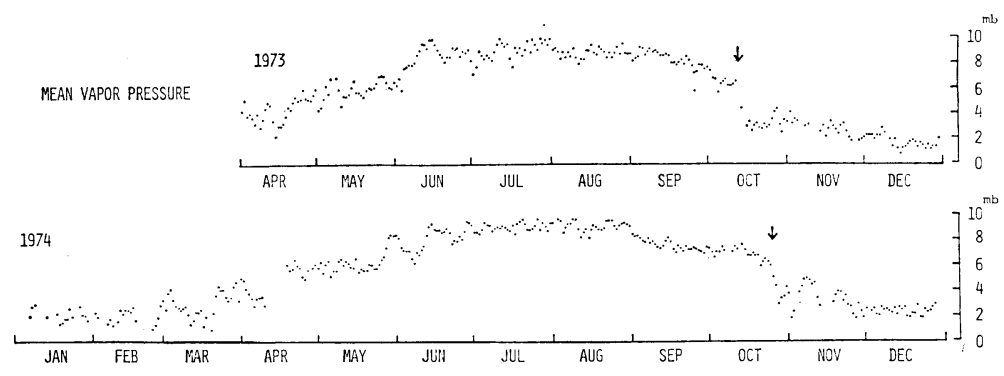

(A)

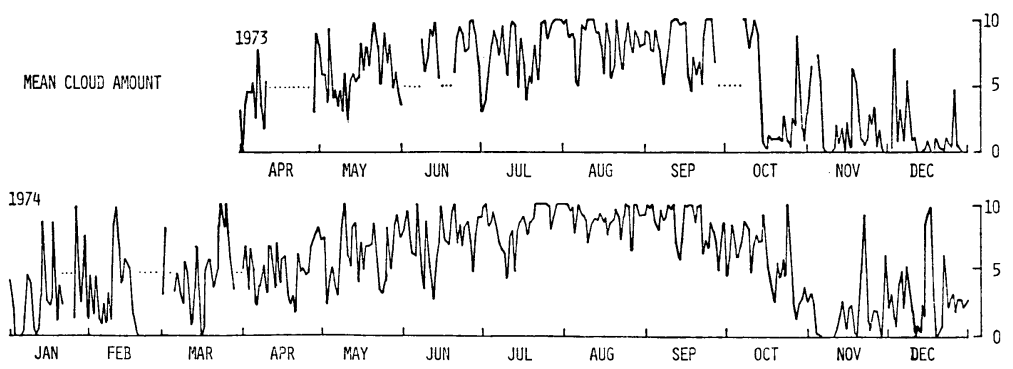

(B)

Fig. 3. Seasonal variation of daily mean vapor pressure and daily mean cloud amout at Lhajung.

unstable condition caused by the combination of moist air at the lower level and upper level strong divergence by the STJ pointed out by Ramaswamy
(1956) (Fig. 4).

3-2 Transition to the monsoon season. In May, the subtropical high began to appear 


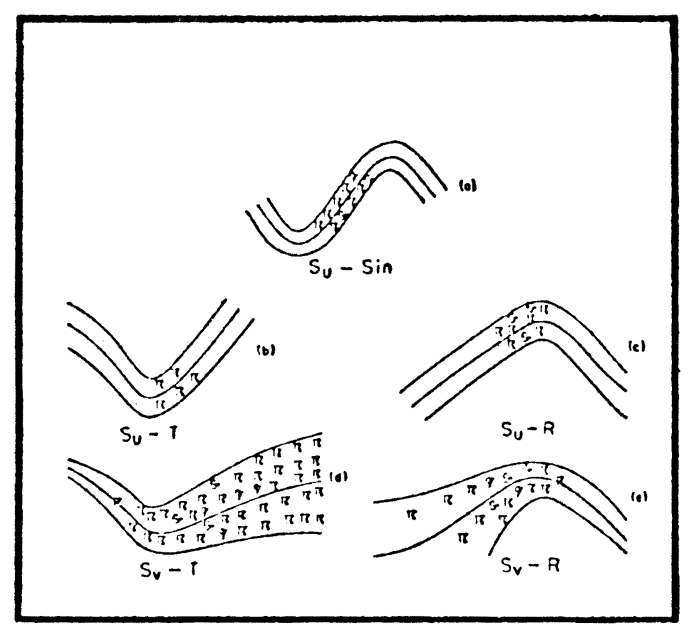

after Ramaswamy (1956)

Fig. 4. Large scale convection in northern India and Pakistan in relation to upper tropospheric contour pattern (After Ramaswamy, 1956).

over Tibet temporarily but also it disappeared temporarily with the progression of the deep westerly troughs. This "struggle" between warm subtropical high and cold westerly troughs continued through May and even in June. However, as the STJ itself retreated north of Tibet at an earlier time (from the end of April through the middle of May), westerly troughs invading up to nolthern India was not associated with the core of strong wind in this stage of the season. Snowfall entirely changed to rainfall at the end of May (May 22 in 1973, May 26 in 1974) at Lhajung, but above the firn lines of the glaciers in this region (about 5300 to $5500 \mathrm{~m}$ ), snowfall is predominant througout the year (Ageta, 1976). In June the vapor pressure rapidly increased and the frequency of cloudiness by cumulus clouds increased. The Tibetan High gradually increased its strength, still sometimes disturbed by westerly troughs. The transitional stage in the development of the Tibetan High is clearly indicated in Fig. 2-a, where the north-south movement of the 5820 $\mathrm{m}$ contour is a good index of the approach of the monsoon season. In this region, a "monsoon burst" was not noticed in the trend of daily mean cloud amount (Fig. 3) or frequency of cloudiness (Fig. 2) corresponding with the gradual intensification of the Tibetan High. However, monsoon rainfall characterized as a series of rainly days seems to have begun simultaneously with the first appearance of a low pressure area over northern India $\left(20^{\circ}-30^{\circ} \mathrm{N}\right)$, as is shown in the appearance of another $5820 \mathrm{~m}$ contour at the $500 \mathrm{mb}$ level in Fig. 2.

3-3 Active monsoon period.

At the end of June, the Tibetan High at the 500 $\mathrm{mb}$ level indicated by the $5820 \mathrm{~m}$ contour was established and maintained its strength through August or September, which may be considered as the active monsoon period. However, the duration and trend of this period vary greatly from year to year. In 1943, a strong Tibetan High indicated by the closed $5880 \mathrm{~m}$ contour first appeared at the end of June, remained steady until around September 20, and a meriodinally extended high pressure area indicated by the $5820 \mathrm{~m}$ contour could be seen to the end of September. In 1974, on the contrary, the $5820 \mathrm{~m}$ contour appeared only a few times and enclosed only a small area, and the closed $5820 \mathrm{~m}$ contour was often seen through this period. The high pressure area was pushed southward with the disappearance of te southern $5880 \mathrm{~m}$ contour in September.

The daily strength of the Tiberan High indicated by the extension of the $5820 \mathrm{~m}$ and $5880 \mathrm{~m}$ cntours in Fig. 2 also varied quasi-periodically with a period of 10 to 15 days. Cumulus clouds along the Imja valley (cloud type I) usually developed at an earlier time of day and occasionally covered the station all day. The daily mean (cumulus) cloud amount sometimes reached 8090\% (see Fig. 3). Most of the monsoon rainfall fell in this period. In the monsoon season precipitation occurred mainly in the evening through night (Ageta, 1976), but in very cloudy and rainy periods (for example, July 27-30, 1973; July 30August 5, 1975, etc.), rainfall continued most of the day. Cloudiness and rainfall went through "intermittent regimes" and "active regimes" with almost the same periodicity as the daily strength of Tiberan High, but it is noteworthy that the cloudy and rainy weather period tends to correspond to the period of the weak Tibetan High. This feature may suggest that the trend of the daily monsoonal precipitation in Nepal Himalaya is directly related to the oscillation of the Tibetan High.

3-4 End of the monsoon season and the first westerly disturbance.

October is intermediate between the monsoon 
season and the post monsoon season. Precipitation decreased in this month, but a considerable amout of moisture in the air still remained (Fig. 3), cumulus clouds (type I, II) remained during the first half of the month.

The monsoon weather pattern ended abruptly with the first arrival of a westerly disturbance associated with the STJ. In 1973, this upper westerly trough came on October 11, and in 1974 it came on October 24. These disturbances brought about the first snowfall to accumulate on the ground at least over $4200 \mathrm{~m}$. Especially, the disturbance of 1973 caused heavy snowfall with a total accumulation of $41 \mathrm{~cm}$ (76 mm with equivalent precipitation) for 2 days, and was associated with thunder and lightning, which indicated strong convective activity. As the STJ at the $300 \mathrm{mb}$ level was not so strong in this case, the heavy convective snowfall might be caused mainly by the invasion of cold air in the middle troposphere as is seen in the $500 \mathrm{mb}$ contour map (Fig. 5). The present author observed the case of 1974 at Everest Base Camp $(5300 \mathrm{~m})$. On October 23, altocumulus and altostratus first passed from SSW to NNE at high speed (60-70 knots as estimated from the $300 \mathrm{mb}$ chart), extending all over the sky. Successively, altocumulus lenticularis and cirro-cumulus frequently appeared and flowed to the NNE. Over Sagarmatha and Nuptse mountains jellyfish-like alto- cumulus clouds also began to appear. In the afternoon, over the southern sky, plumes (like cumulonimbus) rapidly developed showing the strong upper level divergence caused by the STJ. It snowed from that night until the early morning of October 25, with an accumulation of $5-6 \mathrm{~cm}$.

Just after these snowfall days both in 1973 and 1974 , the weather entirely changed to the postmonsoon type. Therefore, monsoon retreat occurs rapidly in this region in contrast with "monsoon burst".

\section{3-5 Typical postmonsoon period.}

Fine and clear days of typical postmonsoon weather predominated from the middle of October to the end of December in 1973, and from the end of October to the end of November in 1974. In this period, the STJ was not clearly developed at the $500 \mathrm{mb}$ level, although the STJ at $300 \mathrm{mb}$ was already over northern India. A quasi-stationary ridge appeared over Tibet and the Himalayas (Fig. 5). Because of the extremely dry air mass advected by the first westerly trough, formation of cumulus clouds (type I and II) ceased. Clear days without any clouds were frequent in the first half of November. It was pointed out that some of the precipitation in the later part of monsoon season falls under the influence of the upper westerly current (Ramaswamy, 1956; Reiter and Heuberger, 1960). Therefore, if we define one series of cloudiness

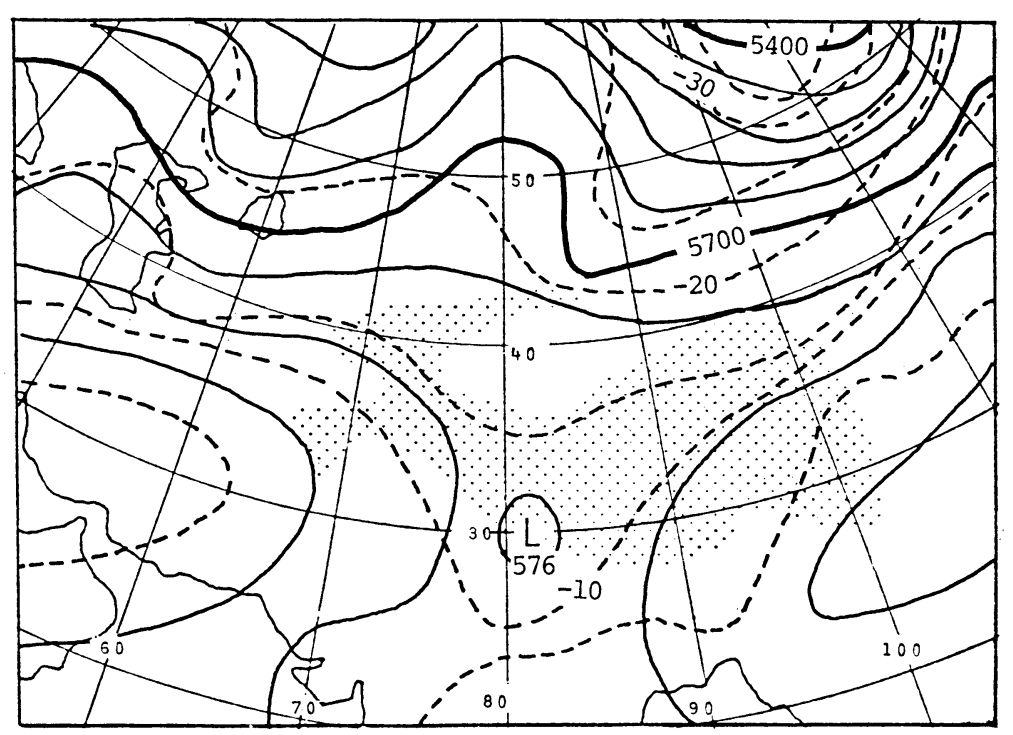

Fig. 5. $500 \mathrm{mb}$ weather chart at $1200 \mathrm{GMT}$ on October $12,1973$. 


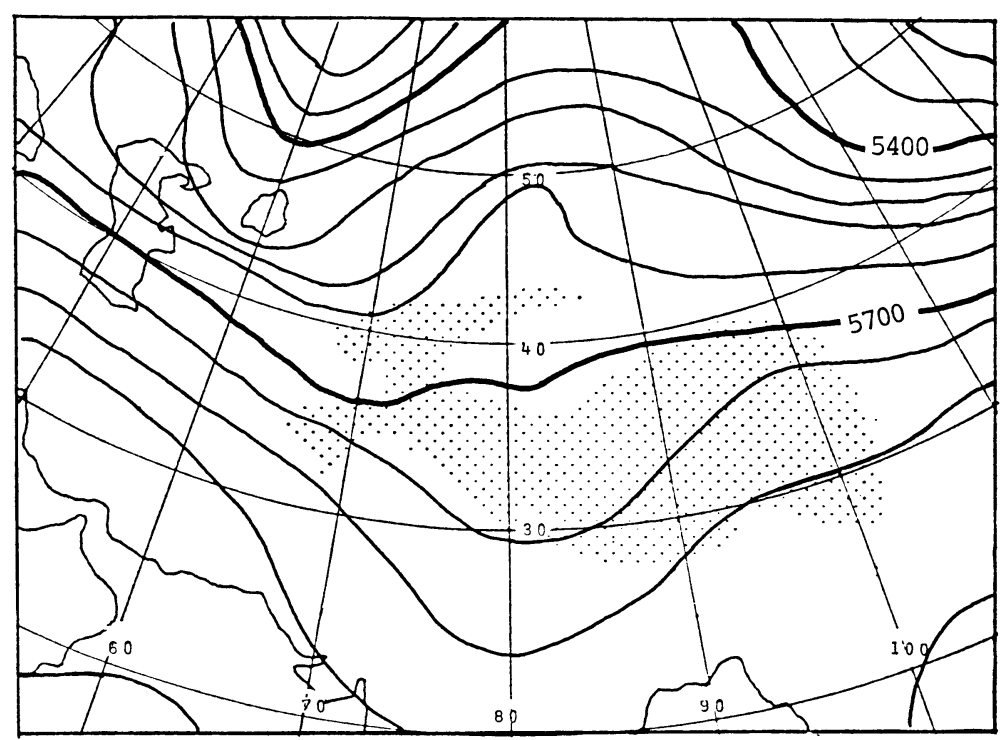

Fig. 6. $500 \mathrm{mb}$ weather chart at $1200 \mathrm{GMT}$ on November 11, 1974 .

and precipitation shown in Fig. 2 and Fig. 3 and Figures of Inoue (1973) as the monsoon season, not the change of the upper flow from the easterly to the westerly but the sudden decrease of moisture (see Fig. 3) seems to correspond to the seasonal change from monsoon to postmonsoon.

This dry and fine weather was gradually modified to the winter weather regime whenever an upper westerly trough passed over this region. How long it lasts may depend on the strength of the STJ. In 1973, the STJ at the $500 \mathrm{mb}$ level was finally settled over the south of Tibet on December 1, but it was so weak that dry and fine weather lasted through December. In 1974, on November 11 completely clear weather was interrupted by the appearance of upper clouds (Cc, Ac, As) flowing rapidly from SSW to NNE and of lenticular clouds (altocumulus lenticularis) over several of the highest peaks (Sagarmatha, Lhotse and Cho Oyu), with the approach of the upper trough. Since that day, the STJ at $500 \mathrm{mb}$ was also fixed south of the Himalayas (Fig. 6) and cumulus clouds were regularly found in the lee of the several large peaks over $8000 \mathrm{~m}$, indicating the flow of a strong STJ over the Himalayas. Through the post monsoon season westerly troughs provided little or no snowfall but only the appearance of upper clouds or the weak formation of cumulus clouds (type I). The reason for these "dry" troughs is in addition to the extremely dry air that they are not yet associated with relatively cold air from the polar region.

3-6 Winter weather regime.

The fine weather regime of the postmonsoon period ended with the snowfall to some extent caused by westerly troughs accompanied by cold outbreaks embedded in the STJ (over 50 knots at $500 \mathrm{mb}$ and over 80 knots at $300 \mathrm{mb}$ in many cases), on January, 14, 1974 and on December $15-17$, 1974. Thereafter, upper level troughs passing over this region often caused snowfall, occasionally with accumulation over $10 \mathrm{~cm}$. Especially in 1975, westerly troughs with snowfall passed frequently with a periodicity of about 45 days, as is clearly shown in Fig. 2-d.

Precipitation in winter fell at or ahead of troughs, as with the westerly disturbances in other seasons, but the weather changes in winter with the approach of troughs were, in most cases, different from those in other seasons. On the approach of a trough, first the sky was covered with upper clouds (mainly cirrus fibratus, the typical jet stream clouds, or cirro-cumulus). Within a day afterward, alticumulus, altostratus or stratocumulus at high altitude $(6000-7000 \mathrm{~m})$ covered the whole sky, gradually lowering cloud bottoms until hiding the lower peaks $(5500-6000$ $\mathrm{m})$. At last, these clouds alternated with nimbostratus, mixing with stratocumulus simultaneously coming up through the Imja valley, and snowfall 


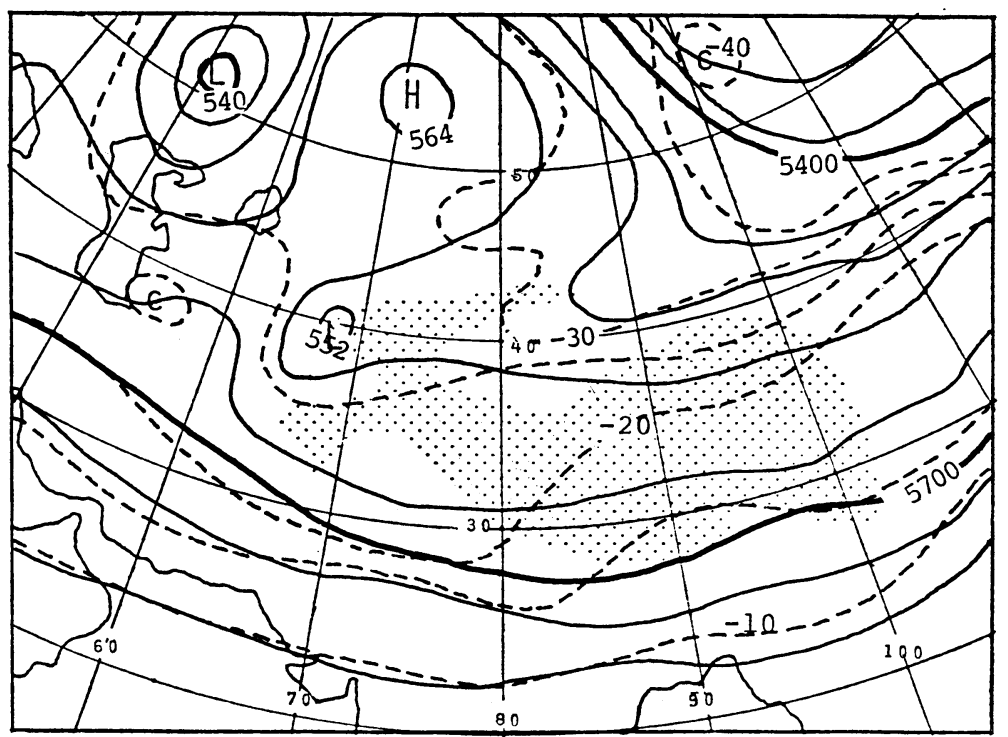

Fig. 7. $500 \mathrm{mb}$ weather chart at $1200 \mathrm{GMT}$ on December 16, 1974.

followed. This pattern of weather change undoubtly indicates that westerly disturbances in winter are baroclinic disturbances though they do not have aclear frontal system. This feature is also identified in the chart of the $500 \mathrm{mb}$ level. For example, in the case of December, 16-18, 1974 (Fig. 7), isothermal lines intersect contour lines ahead of the trough over the southern part of Tibet. In this case, precipitation at Kathmandu ocurred not from nimbostratus but from convective clouds with thunder and lightning (Nakajuma, 1976).

It is well known that westerly disturbances in winter sometimes cause convective precipitation over northern India and along the foot of the Himalayas as a result of the interaction of cold air in the middle or upper troposphere from the inner continent and warm and humid air in the lower troposphere from the ocean (Mooley, 1957). In this region, on the other hand, in most cases from December to March, snowfall was brought about with a weather pattern similar to that of December 16-18, 1974. The baroclinicity of the disturbances over this region may be explained as follows: as it is assumed that even in winter the south-east part of the Tibetan Plateau acts as a weak heat source (staff Members, Academia Sinica, 1957-58; Flohn, 1968), the air temperature near the surface and in the lower troposphere (the $500 \mathrm{mb}$ level is the lower troposphere over the Himalayas and the Tibetan Plateau) may regularly be higher than that of the same level in surrounding regions. Accordingly, if cold air associated with a westerly trough breaks out over the southern Himalayas in the middle troposphere, a large horizontal temperature contrast (baroclinicity) may be produced at the same level around the southern slope of the highland Himalayas near southeast Tibet, while a vertical tempetature contrast may be predominant over northern India. This suggestion is schematically illustrated in Fig. 8.

3-7 End of the winter season.

In 1974, the winter weather regime dominated by westerly troughs embeded in a strong STJ suddenly changed late in March. On March 19, the station was swept by a strong northerly foehn wind with an hourly mean speed of $25 \mathrm{~m} / \mathrm{sec}$ at its peak (Inoue, 1976), caused by the appearance of a blocking anticyclone over the PamirKarakorum region. On March 25, this blocking system developed to become a cut off low (Fig. 9, which provided heavy snowfall in this region through 4 days of March 24-27 with an accumulation of about $20 \mathrm{~cm}$. With the slow passage of the blocking system, the STJ at the $500 \mathrm{mb}$ level moved from its steady location and rapidly retreated to the north of Tibet, and also the moisture in the air gradually increased (Fig. 3). Winter was over. 


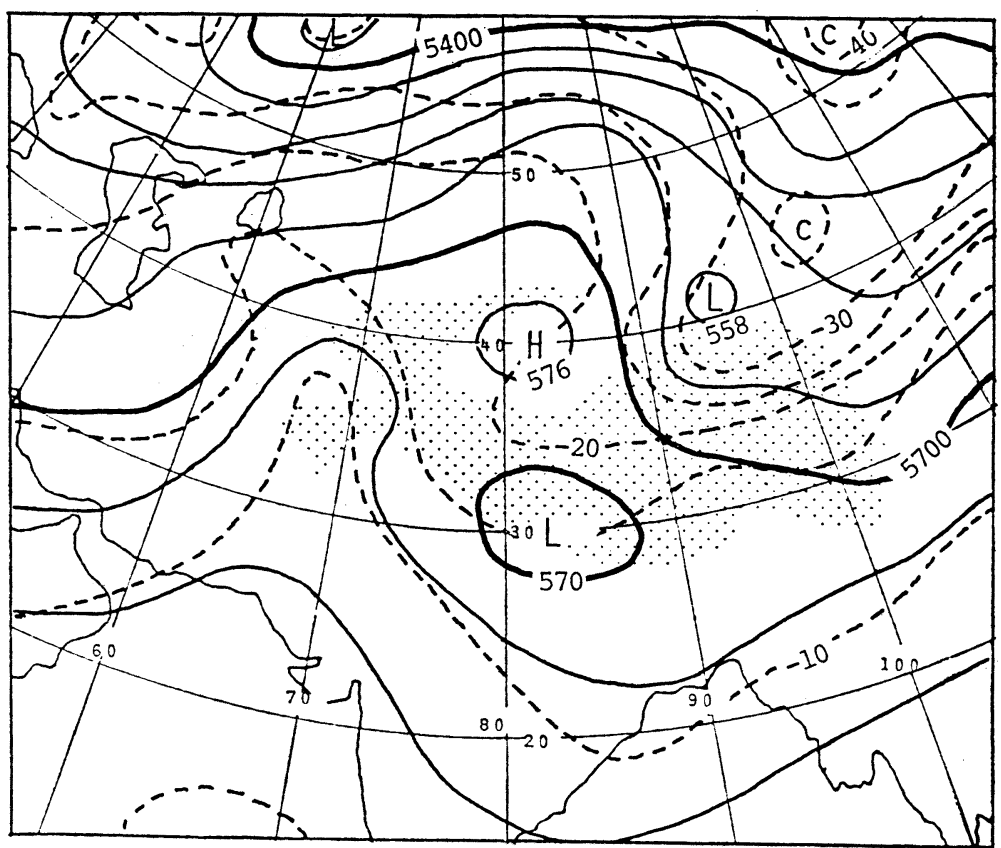

Fig. 9. $500 \mathrm{mb}$ weather chart at $1200 \mathrm{GMT}$ on March 25, 1974 .

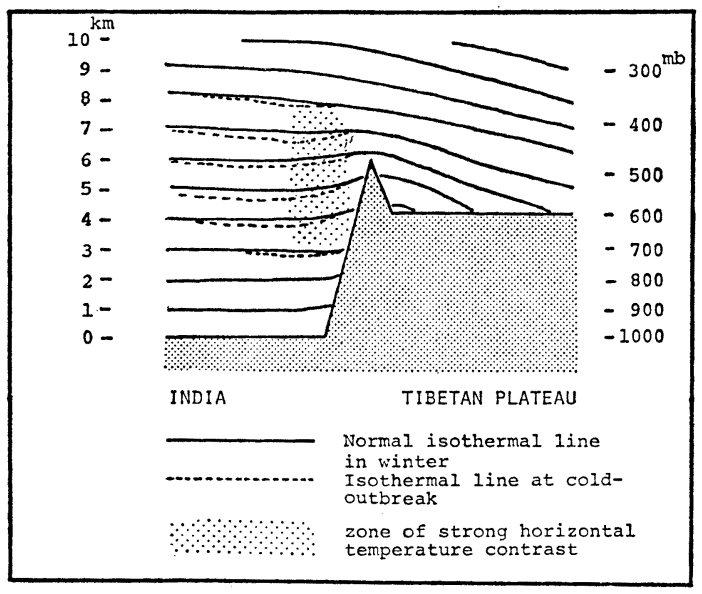

Fig. 8. Schematic pattern of baroclinic feature over the Himalayas and vertical instability over northern India.

\section{Summary and remarks}

Some results of the review of the seasonal weather variation for 2 years at Lhajung weather station $(4420 \mathrm{~m})$ in Khumbu region are summarized here. Main factors for the seasonal variation are; 1) The Tibetan High in monsoon season and subtropical jet stream in other seasons and 2) Moisture supply to this region from Indian
Ocean.

1) The weather (precipitation and cloud phenomena) in the high-altitude Himalayas can be explained by the seasonal trends of two factors; (i) The Tibetan High in the monsoon season and the strength and location of the STJ in other seasons; (ii) The moisture supply to this region from the Indian Ocean area.

2) Precipitation and cloudiness in each season are due to the combination of these three factors, namely:

Premonsoon: the moisture gradully increases, while the influence of the STJ gradually weakens. Precipitation is occasionally caused by the release of latent instability when the STJ basses through this region.

monsoon: the moisture reaches its maximum, and precipitation is caused by the influence of the Tibetan High and the monsoon trough over northern India.

postmonsoon: the air becomes extremely dry and the upper westerly flow is still weak; Upper clouds or thin cumulus clouds (type I) appear on approaching troughs.

winter: the air maintains its dryness, but occasionally snowfall is provided by upper westerly troughs with a strong STJ. These are baroclinic 
disturbances.

At the rapid transitions from monsoon to postmonsoon and from winter to premonsoon, deep westerly troughs in the STJ play an important role in changing the season, occasionally causing a large amount of precipitation.

3) The seasonal weather variation seems to vary considerably from year to year, especially the monsoon and winter weather regimes, corresponding to the strength of the Tibetan High and the STJ in each year.

Some characteristics of the seasonal weather variation for 2 years are roughly summarized in this report. Many unsolved problems are raised, in connection with how the large-scale atmospheric circulation over the Eurasian continent influences the weather phenomena in the high-altitude Himalayas over $4000 \mathrm{~m}$. Especially the relationship between the Tibetan High and monsoonal precipitatation, and the mechanism of westerly disturbances providing a large amount of precipitation, should be studied on the basis of observational data and more detailed synoptic data, considering the effects of high altitide and the complex orography of the Himalayas on the local atmospheric circulation.

\section{References}

Ageta, Y. (1976): Characterictics of the precipitation during the monsoon season in Khumbu Himal, in this issue.

Flohn, H. (1968): Contribution to the meteorology of the Tibetan Highlands. Dept. Atmos. Sci., Colorado State Univ. Atmos. Sci. Paper, No. 130.

Higuchi, H., J. Inoue and Y. Ageta (1975): Kisho to Hyoga, Yalung Kang Gakujutsu Chosa Hokoku [Scintific Report of Yalung Kang Expedition, Academic Alpine Club of Kyoto University], 3344.

Inoue, J. (1976): Climate of Khumbu Himal, in this issue.

Koteswaram, P. (1958): The easterly jet streams on the tropics. Tellus, 10, 43-57.

Mooley, D.A. (1957): The role of Western Distur- bances in the production of weather over India during different seasons. Indian Journal of Meteorology and Geophsics, 8, 253-260.

Mueller, F. (1959): Eight months of glacier and soil research in the Everest region. The mountain world, 191-208.

Murakami, T. (1958): The sudden change of upper westerlies near the Tibetan Plateau at the beginning of summer monsoon. Journal of Meteorological Society of Japan, 36, 239-247.

Murakami, T., R.V. Godbole, and R.R. Kelkar (1970): Numerical simulation of monsoon along $80^{\circ} \mathrm{E}$. In. Proc. Conf. Summer Monsoon Southeast Asia (C.S Ramage edi.), Navy Weather Reserch Facility, Norfolk, 39-51.

Nakajima, C. (1976): Synoptic analyses of the precipitation in Nepal in 1974, in this issue.

Oi, S. (1954): Manaslu no Kisho (Weather around Manaslu). Sokko Jiho, 21, 235-261, 278-286, 315-323.

Osada, M. (1971): Everest no Kisho (Weather aroud Mt. Everest), the record of premonsoon in 1970, Report of Japanese Mt. Everest Expedition, Part II Scientific Report, 99-132.

Pisharoty, P.R. and B.N. Desai (1956): "Western Disturbances" and Indian weather. Indian Journal of Meteolology and Geophysics, 7, 331-331.

Ramage, C.S. (1952): Relationship of general circulation to normal weather over Asia and the western Pacific during the cool season. Journal of Meteorology, 9, 403-408.

Ramaswamy, C. (1956): On the sub-tropical jet stream and its role in the development of large-scale convection. Tellus, 8, 26-60.

Reiter, E.R. and H. Heuberger (1960): A synoptic example of the retreat of the Indian summer monsoon. Georgafiska Annaler, 42, 17-35.

Staff Members, Academia Sinica (1957-58): On the general circulation over eastern Asia. Tellus, 9, 432-446, 10, 58-75, 299-312.

Yeh, T.C. (1950): The circulation of the high troposphere over China in the winter of 1945-46. Tellus, 2, 173-183.

Yin, M.T. (1949): A synoptic-aerogic study of the summer monsoon over India and Burma. Journal of Meteorology, 6, 393-400. 